\title{
A NOTE ON THE DRAG FOR FLUIDS OF GRADE THREE
}

\author{
K. R. RAJAgOPAL \\ Department of Applied Mechanics and Engineering Science, The University of Michigan, \\ Ann Arbor, MI 48109, U.S.A.
}

(Received 13 February 1979)

\begin{abstract}
An expression is obtained for the traction vector $t$ on a solid surface which is adjacent to an incompressible fluid of grade three which is compatible with thermodynamics. It is found that unlike fluids of grade two wherein there is no additional drag due to the non-Newtonian nature of the fluid for bodies with certain geometric symmetries (e.g. sphere), fluids of grade three provide an additional drag which is of the same sign as that provided by the viscous terms, provided certain symmetry conditions are met by the velocity field.
\end{abstract}

\section{INTRODUCTION}

The Cauchy stress $\mathbf{T}$ for an incompressible homogeneous fluid of third grade is assumed to be related to the fluid motion as follows [1]

$$
\mathbf{T}=-p \mathbf{l}+\mu \mathbf{A}_{1}+\alpha_{1} \mathbf{A}_{2}+\alpha_{2} \mathbf{A}_{1}^{2}+\beta_{1} \mathbf{A}_{3}+\beta_{2}\left[\mathbf{A}_{1} \mathbf{A}_{2}+\mathbf{A}_{2} \mathbf{A}_{1}\right]+\beta_{3}\left(\operatorname{tr} \mathbf{A}_{1}^{2}\right) \mathbf{A}_{1}
$$

where $\mathbf{A}_{1}, \mathbf{A}_{2}$ and $\mathbf{A}_{3}$ are the first three Rivlin-Ericksen tensors, $\mu$ the viscosity, $\alpha_{1}$ and $\alpha_{2}$ the normal stress moduli and $\beta_{1}, \beta_{2}$ and $\beta_{3}$ material moduli which resemble shear dependent viscosity. The $-p l$ is the constitutively indeterminate spherical stress due to the constraint of incompressibility. If fluids of third grade are to undergo motions which are compatible with thermodynamics, namely meet the restrictions imposed by the Clausius-Duhem inequality and the assumption that the free energy density of the fluid be a minimum when the fluid is locally at rest, then the material moduli have to meet the following restrictions $\dagger$ [2]

$$
\mu \geqslant 0, \quad \alpha_{1} \geqslant 0, \quad \beta_{1}=\beta_{2}=0, \quad \beta_{3} \geqslant 0
$$

and

$$
-\sqrt{24 \mu \beta_{3}} \leqslant\left(\alpha_{1}+\alpha_{2}\right) \leqslant \sqrt{24 \mu \beta_{3}} .
$$

In this analysis, we shall be concerned with third grade fluids represented by (1.1) subject to the constraints imposed by (1.2). Firstly, we shall obtain an expression for the traction vector $t$ on a solid surface adjacent to an imcompressible homogeneous fluid of third grade by using the results of Berker [3], [4]. Next, we shall obtain certain qualitative results on the drag due to the flow of a third grade fluid. It was found [5], that the drag due to the uniform creeping steady flow of a second grade fluid is the same as the classical Stokesian drag for bodies with appropriate symmetries, showing that the drag was not influenced by the non-Newtonian nature of the fluid. However, such is not the case for the drag due to the flow of an incompressible third grade fluid. We are able to show for bodies of certain symmetry that the additional drag is of the same sign as the drag due to the terms which contain the coefficient of viscosity $\mu$.

+If $\beta_{3}=0$, then we obtain the special subclass of second grade fluids. We note that $\beta_{3}=0$ implies that $\left(\alpha_{1}+\alpha_{2}\right)=0$. 


\section{TRACTION AND DRAG}

We now proceed to derive an expression for the traction t on a solid surface adjacent to an incompressible homogeneous third grade fluid in steady motion. By virtue of (1.1) and (1.2), we see that the Cauchy stress $\mathbf{T}$ for an incompressible homogeneous third grade fluid is given by

$$
\mathbf{T}=-p \mathrm{l}+\mu \mathbf{A}_{1}+\alpha_{1} \mathbf{A}_{2}+\alpha_{2} \mathbf{A}_{1}^{2}+\beta_{3}\left(\operatorname{tr} \mathbf{A}_{1}^{2}\right) \mathbf{A}_{1}
$$

where

$$
\mathbf{A}_{1} \equiv(\operatorname{grad} \mathbf{v})+(\operatorname{grad} \mathbf{v})^{\mathrm{T}}
$$

and

$$
\mathbf{A}_{2} \equiv \dot{A}_{1}+\left[\mathbf{A}_{1}\right][\operatorname{grad} \mathbf{v}]+[\operatorname{grad} \mathbf{v}]^{\mathrm{T}}\left[\mathbf{A}_{1}\right]
$$

The dot denotes material time differentiation.

Thus, by (2.2), the traction vector $t$ is given through

$$
\mathbf{t}=\mathbf{T}^{\mathrm{T}} \mathbf{n}=\left\{-p l+\mu \mathbf{A}_{1}+\alpha_{1} \mathbf{A}_{2}+\alpha_{2} \mathbf{A}_{1}^{2}+\beta_{3}\left(\operatorname{tr} \mathbf{A}_{1}^{2}\right) \mathbf{A}_{1}\right\} \mathbf{n}
$$

where $\mathbf{n}$ is the unit outward normal.

Next, we make use of the observations of Berker [3], [4] that for an incompressible fluid flowing past a solid surface

$$
\mathbf{A}_{1} \mathbf{n}=\omega \times \mathbf{n}
$$

where

$$
\omega=\operatorname{curl} \mathbf{v}
$$

and

$$
\mathbf{A}_{1}^{2}=|\omega| \mathbf{m} .
$$

On substituting (2.3) and (2.4) into (2.2), we obtain $†$

$$
\mathbf{t}=\left[-p+\left(2 \alpha_{1}+\alpha_{2}\right)|\omega|^{2}\right] \mathbf{n}+\left(\mu+\beta_{3} \text { tr } \mathbf{A}_{1}^{2}\right) \omega \times \mathbf{n} .
$$

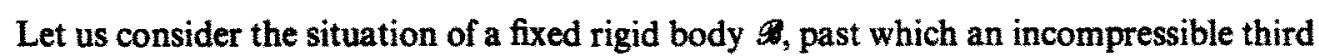
grade fluid which is compatible with thermodynamics, is flowing; further, let us suppose that the fluid is in steady creeping motion and that the motion is uniform at infinity Thus the flow tield is governed by

$$
\mathbf{v}=\mathbf{0} \text { on } \partial s
$$

and

$$
\mathbf{v} \rightarrow \text { const. } \mathbf{k} \text { as }|\mathbf{x}| \rightarrow \infty \text {. }
$$

The drag force $\mathrm{D}$ on $\mathrm{is}$ then given by

$$
D=\int_{0,} t \cdot k d a=\int_{a}\left\{(-p \mathbf{n}+\mu \omega \times \mathbf{n})+\left(2 \alpha_{1}+\alpha_{2}\right)|\omega|^{2} \mathbf{n}+\beta_{3}\left(\operatorname{tr} \mathbf{A}_{1}^{2}\right) \omega \times \mathbf{n}\right\} \cdot \mathbf{k d} a
$$

Suppose the body 9 under consideration is symmetric under the transformation

$$
\left(x_{1}, x_{2}, x_{3}\right) \rightarrow\left(-x_{1},-x_{2},-x_{3}\right)
$$

relative to a fixed rectangular cartesian co-ordinate system. The flow past the body is uniform and parallel to $k$, a unit vector in the $x_{3}$ direction, at infinity. Further, suppose that

$¥$ The results obtained regarding the form of the traction and the nature of the drag for fluids of second grade [5], can be obtained from our result by setting $\beta_{3}=0$.

fIf the flow were unsteady there would be an additional term $\alpha_{1}(\partial \omega / \partial t) \times n$.

$\ddagger$ We assume that the flow is slow enough that the uniqueness Theorem of [2] applies for such flows. 
the velocity field $\mathbf{v}$ meets the following symmetry property $\S$

$$
\mathbf{v}(\mathbf{x})=\mathbf{v}(-\mathbf{x}) \text {, }
$$

It follows from the symmetry of the body that

$$
\mathbf{n}(\mathbf{x})=-\mathbf{n}(-\mathbf{x}) \text {. }
$$

It is easy to show that (2.7) implies that

$$
|\omega|^{2}(\mathbf{x})=|\omega|^{2}(-\mathbf{x})
$$

and

$$
\left|\mathbf{A}_{1}\right|^{2}(\mathbf{x})=\left|\mathbf{A}_{1}\right|^{2}(-\mathbf{x}) \text {. }
$$

Then, one can see that the equations (2.8) and (2.9) imply that

$$
\int_{\partial a}\left(2 \alpha_{1}+\alpha_{2}\right)|\omega|^{2} \mathbf{n} \cdot \mathbf{k} \mathrm{d} a=0 .
$$

Next, by means of a very simple calculation one can verify that (2.7) and (2.8) imply that

$$
\omega(\mathbf{x}) \times \mathbf{n}(\mathbf{x}) \cdot \mathbf{k}=\omega(-\mathbf{x}) \times \mathbf{n}(-\mathbf{x}) \cdot \mathbf{k} .
$$

Since

$$
\operatorname{tr} A_{1}^{2}(x) \geqslant 0 \forall \mathbf{x} \varepsilon \partial \mathscr{B}
$$

we see that both the integrals

$$
\int_{\partial \boldsymbol{g}} \omega \times \mathbf{n} \cdot \mathbf{k} \mathrm{d} a
$$

and

$$
\int_{\partial a}\left(\operatorname{tr} \mathbf{A}_{1}^{2}\right) \omega \times \mathbf{n} \cdot \mathbf{k} d a
$$

have the same sign, by virtue of (1.2), (1.4), (2.10) and (2.12).

Thus, the drag $D$ for the flow of a third grade fluid past a body with the symmetry considered is given by

$$
D=\int_{\partial g}(-p n) \cdot \mathbf{k} \mathrm{d} a+\int_{\partial g} \mu(\omega \times n) \cdot \mathbf{k} \mathrm{d} a+\int_{\partial \Phi} \beta_{3}\left(\operatorname{tr} \mathbf{A}_{1}^{2}\right) \omega \times \mathbf{n} \cdot \mathbf{k} \mathrm{d} a
$$

where the last two integrals have the same sign. This additional drag is the drag due to the viscous nature of the term $\beta_{3}$. Such an additional drag would not be present for fluids of second grade wherein $\beta_{3} \equiv 0$.

\section{REFERENCES}

1. C. Truesdell and W. Noll, Non-Linear Field Theories of Mechanics, Flügge's Handbook der Physik, 111/3. Springer (1965).

2. R. L. Fosdick and K. R. Rajagopal, Thermodynamics and Stability of Third Grade Fluids. (to be published) Proc. R. Soc. (1979).

3. R. Berker, Sur certaines properiete's de l'effort qui s'exerce sur une paroi en contact avec un fluide visqueux C. r. hebd. Séanc. Acad. Paris 232, 148 (1951).

4. R. Berker, Contrainte sur une paroi en contact avec un fluide visqueux classique, un fluide de Stokes, un fluide de Coleman-Noll, C. hebd. Séanc. Acad. Sci., Paris 2855144 (1964).

5. R. L. Fosdick, and K. R. Rajagopal, Uniqueness and Drag for Fluids of Second Grade in Steady Motion, Int. J. Non-Linear Mech. 13, 131 (1978). 
Resume:

On obtient une expression donnant le vecteur de traction $t$ sur une surface solide qui est contigue a un fluide incompressible de degre 3 compatible avec la thermodynamique. On trouve que contrairement aux fluides de degre 2 pour lesquels il $n^{\prime} y$ a pas de trainee additionnelle due a la nature non Newtonienne du fluide pour des corps possedant certaines symetries geometriques (par exemple une sphere), les fluides de degre 3 donnent une trainee additionelle qui est du meme signe que celle fournie par les termes visqueux pourvu que certaines conditions de symetrie soient verifiees par le champ de vitesse.

Zusammenfassung:

Fur eine feste Oberfache in Beruhrung mit einer inkompressiblen Flussigkeit dritter Art, die nach thermodynamischen Regeln zulassig ist, wird ein Ausdruck fur den Oberflachenspannungsvektor $t$ hergeleitet. Es ist bekannt, dass Flussigkeiten szeiter Ärt trotz ihrer nichtnewtonischen Natur keinen zusatzlichen Widerstand fur Korper mit gewissen geometrischen Symmetrien (z. B. Kuge $n$ ) hervorrufen. Im Gegensatz dazu rufen Flussigkeiten dritter Art Einen zusatzlichen Widerstand hervor, der in dieselbe Richtung wie die Zahigkeitsglieder wirkt. Dabei wird angenormen, das das Geschwindigkeitsfeld gewisse symmetrische Bedingungen erfullt. 